\title{
The Prevalence of Hypertension: Role of Hereditary in Young and Obesity in all
}

Anand Narendra Shukla*, Tarun Madan, Bhavesh M Thakkar, Meena Parmar and Komal Shah

U.N. Mehta Institute of Cardiology and Research Center, Ahmedabad, Gujarat, INDIA

"Corresponding author: Shukla A N, U.N. Mehta Institute of Cardiology and Research Center, Ahmedabad, Gujarat, INDIA, Tel: 09825868849; E-mail: dranand1978@yahoo.co.in

Received date: May 07, 2014; Accepted date: June 28, 2014; Published date: July 01, 2014

Copyright: $(2014$ Shukla AN, et al. This is an open-access article distributed under the terms of the Creative Commons Attribution License, which permits unrestricted use, distribution, and reproduction in any medium, provided the original author and source are credited.

\begin{abstract}
The epidemiology study was done to evaluate the prevalence and contributing factors for hypertension in western Indian. Total 3629 patients eligible for study; overall prevalence of hypertension was $26 \%$ and approximately $10 \%$ in younger (<40 yrs) age group. The obesity and sedentary life style plays important role in development of hypertension in overall population while family history of hypertension and obesity influence in younger.
\end{abstract}

Keywords: Hypertension, Prevalence, Obesity, Hereditary

\section{Introduction}

Cardiovascular disease (CVD) is in malignant form in Asian Indians because it affects younger age group $(<40 \mathrm{yrs})$, so the risk factors for the same might appears at an earlier age. Hypertension is an increasingly important medical and public health issue because it is one of the important risk factor for the CVD. The prevalence of hypertension increases with advanced age to the point where more than half of people aged 60 to 69 years old and approximately three fourth of those aged 70 years and older are affected [1].

Data from observational studies involving more than 1 million individuals have indicated that death from ischemic heart disease and stroke increases progressively and linearly from blood pressure (BP) level as low as $115 \mathrm{mmHg}$ of systolic and $75 \mathrm{mmHg}$ of diastolic. For every $20 \mathrm{mmHg}$ systolic or $10 \mathrm{mmHg}$ diastolic increase in $\mathrm{BP}$, there is doubling of mortality from both ischemic heart disease and stroke. The increased risks are present in all age groups ranging from 40 years to 89 years old [1]. Earlier reports also suggest that the prevalence of hypertension is rapidly increasing in developing countries and is one of the leading causes of death and disability. Risk of cardiovascular events in Asian Indians is higher at relatively lower level of blood pressure [2]. In terms of attributable death, raised blood pressure is one of the leading behavioral and physiological risk factor to which $13 \%$ of global deaths are attributed. Hypertension is reported to be the fourth contributor to premature death in developed countries and the seventh in developing countries [2].

\section{Material and Methods}

This cross-sectional study was conducted from $29^{\text {th }}$ Sep 2013 to $7^{\text {th }}$ Oct 2013 at two centers in Ahmedabad. Total 4166 individual participated in this study.

\section{Inclusion criteria}

- Age $>20$ yrs

- Healthy individuals

\section{Exclusion criteria}

- Known case of hypertension and or receiving drug for same currently or in past

- Known case of diabetes and or receiving drug for same currently or in past

- Known case of Ischemic heart disease and or receiving drug for same

\section{- Pregnancy}

Total 4166 individual participated in this study out of which 3629 were eligible for enrolment and data analysis. Detailed clinical evaluation was done which included proper blood pressure measurement; fasting blood was taken for biochemical analysis and anthropometric measurements.

\section{Following tests/evaluation were carried out}

- Height and weight

- Blood pressure measurement

- Resting 12 leads ECG

- Fasting lipid profile, Fasting Blood Sugar, Cretaine and Haemoglobin

The accurate measurement of BP was the sin qua non for part of this study. The mercury equipment, individual properly prepared and positioned. The auscultatory method of BP measurement was used. Person should have been sitting quietly for at least five minutes in chair with feet on the floor and arm supported at the heart level. Use of standard cuff, large bladder for fat arm and small bladder for asthenic arm [1]. For measurement, the bladder was quickly inflated to 20 $\mathrm{mmHg}$ higher than point of disappearance of radial pulse and bladder was deflated slowly at $2 \mathrm{mmHg}$ every second. JNC-VII criteria were used to diagnose hypertension. The family history of hypertension defined as any first-degree family member diagnosed and/or receiving drug therapy for hypertension. 


\section{Analysis}

\begin{tabular}{|l|l|}
\hline & \multicolumn{1}{|c|}{ Blood pressure } \\
\hline Normal $(\mathrm{N})$ & Systolic $<120 \mathrm{mmHg}$ and diastolic $<80 \mathrm{mmHg}$. \\
\hline $\begin{array}{l}\text { Pre-hypertension } \\
\text { (PHTN) }\end{array}$ & $\begin{array}{l}\text { Systolic }>120 \text { to } 139 \mathrm{mmHg} \text { or Diastolic }>80 \text { to } 89 \\
\mathrm{mmHg}\end{array}$ \\
\hline Hypertension (HTN) & Systolic $>140 \mathrm{mmHg}$ or diastolic $>90 \mathrm{mmHg}$. \\
\hline
\end{tabular}

Table 1: Participant divided into three categories according to their blood pressure as per JNC VII: normal blood pressure $(\mathrm{N})$, prehypertension (PHTN) and hypertension (HTN)

The factors contributing for development of hypertension were also evaluated. These factors were family history of hypertension, obesity, sedentary life style, smoking and type-A personality. The analysis of above mention factors were done to assess their significance and relative risk between normal, pre-hypertensive and hypertensive groups.

The population characteristic of this cross sectional study was described using proportions. Univariate analysis method was performed to assess the difference between two groups using Chisquare test. The level of significance was accepted at $\mathrm{p}<0.05$. All the analysis was performed using Medcalc, version 12.2.1.0 (MedCalc Software bvba, Belgium).

The relative risk of the population was calculated using following formula:

$$
\text { Relative risk }(\mathrm{RR})=\frac{\text { Incidence in the affected popualtion }}{\text { Incidence in the unaffected population }}
$$

\section{Results}

Total 3629 participants eligible for study; out of which 1735 (48\%) were below forty years of age. The overall prevalence of hypertension, and pre-hypertension were $26 \%$ and $40 \%$ respectively.

\begin{tabular}{|l|l|l|l|}
\hline & $\begin{array}{l}\text { Total no } \\
\text { (\% of total pt) }\end{array}$ & $\begin{array}{l}<\mathbf{4 0} \text { yrs } \\
\text { (Group: A) }\end{array}$ & $\begin{array}{l}\mathbf{>} \text { (Group: } \mathbf{B}) \\
\text { (Grs }\end{array}$ \\
\hline Normal (N) & $1204(33 \%)$ & $865(50 \%)$ & $339(18 \%)$ \\
\hline Pre-hypertension (PHTN) & $1472(40 \%)$ & $684(39 \%)$ & $788(42 \%)$ \\
\hline Hypertension (HTN) & $953(26 \%)$ & $186(11 \%)$ & $767(40 \%)$ \\
\hline Total & 3629 & 1735 & 1894 \\
\hline
\end{tabular}

Table 2: The prevalence of hypertension was approximately $11 \%$ in $<40$ years of age in contrarily, $>40$ yrs of age groups only $18 \%$ were belong to normal blood pressure category.

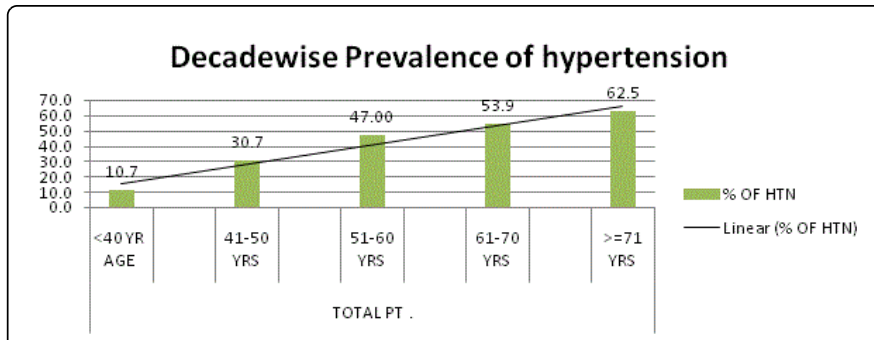

Figures 1: Prevalence of hypertension decade wise shows approximately $10 \%$ in fourth decades, which increase up to three times $(30 \%)$ in fifth decades and more than $50 \%$ prevalence after sixth decades.

The factors contributing towards development of hypertension were analyzed in overall population as well as in younger ( $<40$ years) patient group. These factors were family history of hypertension, obesity (Body Mas Index $>25 \mathrm{~kg} / \mathrm{m}^{2}$ ), smoking, sedentary life style and type-A personality.

All these factors show significant statistical significant difference between normal and pre hypertension in overall population except Type-A personality. The relative risk was higher for obesity (1.51) in compare to other factors (Figure 2, Table 3).

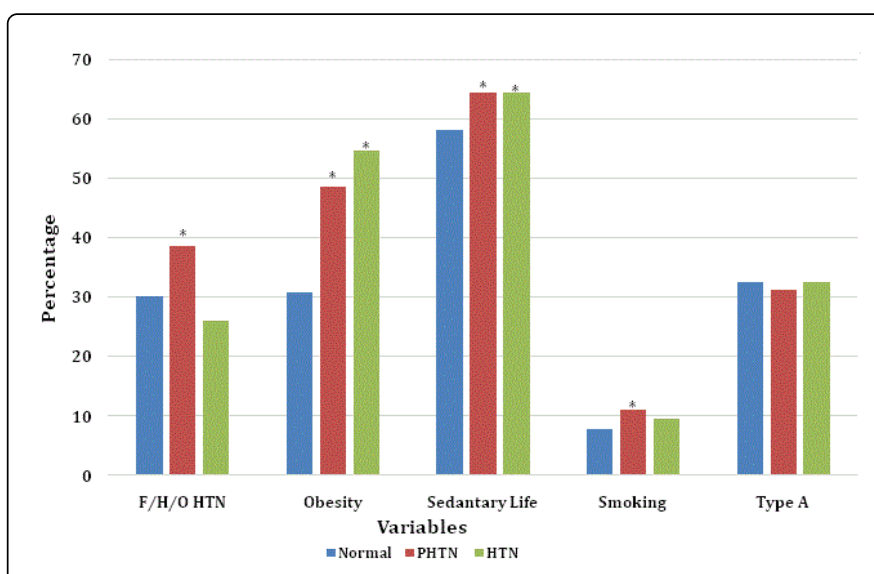

Figure 2: Frequency of contributing risk factors for hypertension in normal, pre-hypertensive and hypertensive population.

Where, F/H/O HTN-Family history of hypertension, PHTN-Prehypertension, HTN-Hypertension, *-Significantly different as compared to normal

In younger pre-hypertensive patient family history of hypertension, obesity, smoking and sedentary life styles shows significant difference between two groups while relative risk was higher with smoking (1.76) and obesity (1.73) compare to other variables (Table 3 and Figure 3).

The younger hypertensive is obese and having positive family history of hypertension compare to normal population; relative risk were higher with both of these variables (Table 3 and Figure 3). 
Citation: Shukla AN, Madan T, Thakkar BM, Parmar M, Shah K (2014) The Prevalence of Hypertension: Role of Hereditary in Young and Obesity in all. J Hypertens 3: 156. doi:10.4172/2167-1095.1000156

Page 3 of 4

\begin{tabular}{|l|l|l|l|l|}
\hline & \multicolumn{2}{|c|}{ Total Population } & \multicolumn{2}{c|}{ Age $\leq 40$} \\
\hline Variables & RR of N \& PHTN & RR of N \& HTN & RR of N \& PHTN & RR of N \& HTN \\
\hline F/H/O HTN & 1.14 & 0.8618 & 1.379 & 1.4788 \\
\hline Obesity & 1.515 & 1.773 & 1.7377 & 1.986 \\
\hline Sedentary Life & 1.105 & 1.1069 & 1.112 & 1.0766 \\
\hline Smoking & 1.428 & 1.224 & 1.767 & 1.472 \\
\hline Type A & 0.955 & 0.997 & 0.959 & 1.483 \\
\hline
\end{tabular}

Table 3: Relative risk of contributing factors for PHTN and HTN in overall population and young (age $\leq 40$ ) population

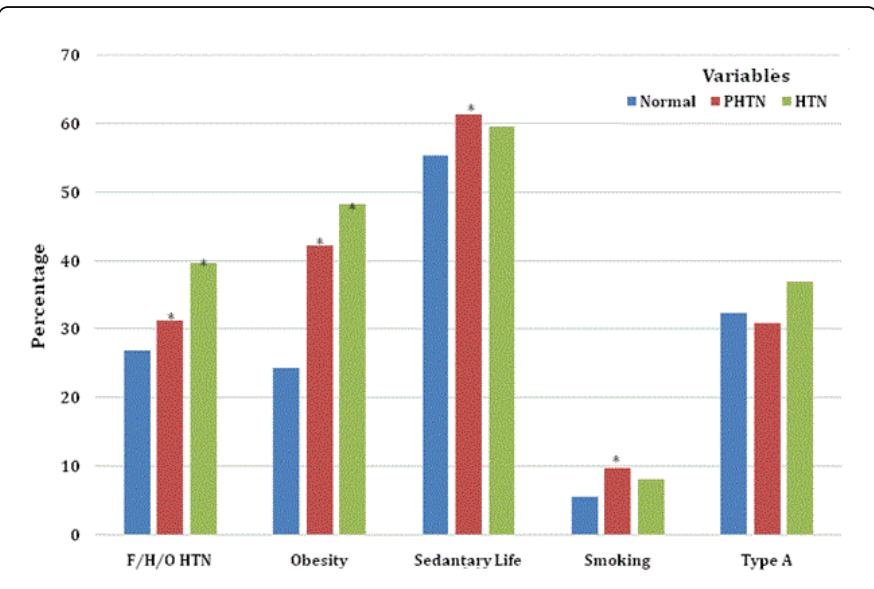

Figure 3: Frequency of contributing risk factors for hypertension in normal, pre-hypertensive and hypertensive population in age groups $\leq 40$, Where, $\mathrm{F} / \mathrm{H} / \mathrm{O}$ HTN-Family history of hypertension, PHTN-Pre-hypertension, HTN-Hypertension, *-Significantly different as compared to normal

In elderly hypertensive population obesity showed significant difference and relative risk for development of hypertension was higher with obesity (1.77) compare to other variables (Figure 4).

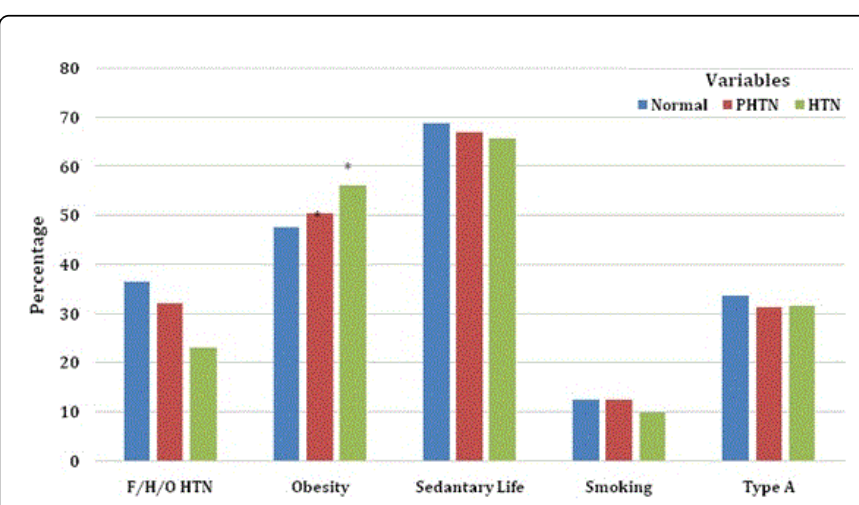

Figure 4: Frequency of contributing risk factors for hypertension in normal, pre-hypertensive and hypertensive population in age groups $>40$

\section{Discussion}

Cardiovascular disease was the largest cause of deaths in males (20.3\%), as well as female (16.9\%) and lead to 2 million deaths annually. The population attributable risks were different with greater importance of hypertension and lesser importance of diabetes and lipids [3]. The Atlas of heart disease and stroke has demonstrated a sustained increase in mean blood pressure level from a low $120 \mathrm{mmHg}$ to $130 \mathrm{mmHg}$ in year 1997 as compare to 1942 . Further modelled data project that $107.3 \mathrm{~m}$ million men and 106.2 million women will suffer from hypertension by the year 2025 [4].

Hypertension is leading attributable risk factor in INTERSTROKE study for thrombotic or hemorrahagic strokes (34.6) while forth contributable risk factor for acute myocardial infarction as per INTERHEART study. The overall prevalence of hypertension has risen from low of $4.3 \%$ in 1963 to as high as approximately $50 \%$ in specific community of rajasthan and kerala [6].

Table 4 shows prevalence of hypertension in different study from 1995 to 2008 ; range of prevalence between $20 \%$ to $47.9 \%$.

\begin{tabular}{|l|l|l|l|l|l|}
\hline First author & Year & \multicolumn{1}{|c|}{ Place } & Age (Yrs) & \multicolumn{1}{|c|}{$\begin{array}{c}\text { Sample } \\
\text { size }\end{array}$} & $\begin{array}{c}\text { Prevalenc } \\
\text { e }\end{array}$ \\
\hline Gupta R & 1995 & Jaipur & $>20$ & 2212 & 30.9 \\
\hline Anand MP & 2000 & Mumbai & $30-60$ & 1662 & 34 \\
\hline Gupta R & 2002 & Jaipur & $>20$ & 1123 & 33.4 \\
\hline Shanthirani CS & 2003 & Chennai & $>20$ & 1262 & 21.1 \\
\hline Gupta PC & 2004 & Mumbai & $>35$ & 88653 & 47.9 \\
\hline Prabhakaran D & 2005 & Delhi & $20-59$ & 2935 & 30 \\
\hline Reddy KS & 2006 & National & $20-69$ & 19973 & 27.2 \\
\hline Mohan V & 2007 & Chennai & $>20$ & 2350 & 20 \\
\hline Kaur P & 2007 & Chennai & $18-69$ & 2262 & 27.2 \\
\hline Yadav S & 2008 & Lucknow & $>30$ & 1746 & 32.2 \\
\hline Shukla A & $\mathbf{2 0 1 3}$ & Ahmedabad & $>\mathbf{2 0}$ & $\mathbf{3 6 2 9}$ & $\mathbf{2 6 \%}$ \\
\hline
\end{tabular}

Table 4: Prevalence of hypertension in different study from 1995 to 2008 
Our study is third largest study to evaluate prevalence of HTN and having prevalence about $26 \%$. The prevalence of hypertension has increased in both urban and rural population. In rural population higher prevalence in Rajasthan while urban prevalence doesn't vary significance in different region. The prevalence of HTN was highest in metropolitan cities such as Mumbai and lower in less populated cities [7-10].The decade wise prevalence of hypertension in our study shows progressively increase from approximately $11 \%$ in less than 40 years to more than $50 \%$ after sixth decades [11-14].

The results from our study show that prevalence of hypertension increase as age increase. The family history of hypertension and obesity plays important role in younger hypertensive patient while obesity and sedentary life style were important factors on overall population. As the family history of hypertension is a hereditary and non modifiable factor; obesity and sedentary life style are modifiable risk factors. By increase awareness of exercise and by focusing on prevention of obesity may decrease prevalence of hypertension in the study community.

\section{Conclusion}

The prevalence of hypertension increase with age with overall prevalence in this study was $26 \%$.The family history of hypertension, obesity and sedentary life style appeared to be major factors contributing for development of hypertension. The prevention of obesity may influence in reduction in development of hypertension in study population.

\section{References}

1. James PA, Oparil S, Carter BL, Cushman WC, Dennison-Himmelfarb C et al. (2014) 2014 evidence-based guideline for the management of high blood pressure in adults. Report from the panel members appointed to the eighth joint national committee. (JNC 8) JAMA 311: 507-520.
2. Hypertension Indian guideline (2013) JAPI.

3. Gupta R (2004) Trends in hypertension epidemiology in India. J Hum Hypertens 18: 73-78.

4. Mackay J, Mensah GA (2004) The Atlas of Heart diasease and stroke. World Heart organization Geneva.

5. Deedwania PC, Gupta R (2012) Hypertension in south Asian (2ndedn), Black HR. Eliott WJ edi, A companion text to Brown World Heart Disease, WB saunder.

6. Seventh report of the joint national committee on prevention, detection, evaluation and treatment of high blod pressure (2003) Hypertension 42:1206-1252.

7. Mancia G, De Backer G, Dominiczak A, Cifkova R, Fagard R, et al. (2007) 2007 Guidelines for the management of arterial hypertension: The Task Force for the Management of Arterial Hypertension of the European Society of Hypertension (ESH) and of the European Society of Cardiology (ESC). Eur Heart J 28: 1462-1536.

8. Gupta R, Guptha S, Sharma KK, Gupta A, Deedwania P (2012) Regional variations in cardiovascular risk factors in India: India heart watch. World J Cardiol 4: 112-120.

9. Shah B, Mathur P (2010) Surveillance of cardiovascular disease risk factors in India: the need \& scope. Indian J Med Res 132: 634-642.

10. Sliwa K, Stewart S, Gersh BJ (2011) Hypertension: a global perspective. Circulation 123: 2892-2896.

11. Flack JM (2007) Epidemiology and unmet needs in hypertension. J Manag Care Pharm 13: 2-8.

12. Reddy KK, Rao AP, Reddy TP (2002) Socioeconomic status and the prevalence of coronary heart disease risk factors. Asia Pac J Clin Nutr 11: 98-103.

13. Yusuf S, Hawken S, Ounpuu S, Dans T, Avezum A, et al. (2004) Effect of potentially modifiable risk factors associated with myocardial infarction in 52 countries (the INTERHEART study): case-control study. Lancet 364: 937-952.

14. O'Donnell MJ, Xavier D, Liu L, Zhang H, Chin SL, et al. (2010) Risk factors for ischaemic and intracerebral haemorrhagic stroke in 22 countries (the INTERSTROKE study): a case-control study. Lancet 376: $112-123$. 